\title{
Leprosy in the Republic of Paraguay.
}

$T \mathrm{~T}$ is interesting to hear that active measures are being considered for the development of modern anti-leprosy work in the Republic of Paraguay. We have received a memorandum from Dr. J. Nairn Hay indicating the lines along which measures are to be enforced.

The population of Paraguay is approximately one million, and the number of cases of leprosy is estimated to be between 2,000 and 4,500. This appears to be relatively small, but at the same time there seems to be evidence that the disease is spreading. It is for this reason that the authorities are considering putting into force active measures with regard to the control of the disease. It has been decided to build a colony near Sapucai, on the railway about 80 miles from Asuncion, on a piece of land of about 2,500 acres, excellently suited for the growing of crops and plantations, and with a good water supply. It has been pointed out to us that this decision is due to the far-sighted and. wise attitude taken by Dr. Eusabio Ayala, the President of the Republic, who is being ably and enthusiastically supported by Dr. Justo Prieto, the Minister of Education, and Dr. Ricardo Odriosolo, Dean of the Faculty of Medicine of the National University. The colony will consist of some 36 houses, each accommodating four patients, and a modern treatment block with dispensary and laboratory. Each patient will have his or her own plot of land in which to grow the usual food stuffs, and will be free to live in his or her own house without any restrictions. The point that is being stressed is that patients will be attracted there by persuasion rather than brought by force. This will open up the possibility of giving first place to segregation and treatment on modern lines, and emphasis will be placed on the voluntary attraction of open cases to the settlement.

The main objects of the colony are stated to be as follows :-

(1) A centre for the modern treatment of early and advanced cases.

(2) A centre for research work in leprosy.

(3) A centre for training students and others.

(4) A centre for agriculture-to provide occupation for the patients.

(1) A Centre for Modern Treatment.-As there are some 100 advanced cases already under treatment, provision will have to be made for them. As their health is not good they 
will be housed in a part of the colony where it will be possible to carry out their treatment without difficulty. They will also be allowed sufficient ground to grow the food stuffs to which they are accustomed. As early cases are attracted to the colony, provision will be made for them in other parts of the colony, apart from the advanced cases.

(2) A Centre for Research.-The first object of research will be :-

(a) To ascertain the number of sufferers from the disease in the country.

(b) The districts most infected and the type predominating.

(c) The factors influencing location and type.

(3) A Centre for Training.

(a) For the medical students of the National University-laying stress on the practical rather than on the theoretical side.

(b) For others taking up leprosy.

(4) A Centre for Agriculture.-It is necessary that the patient under, treatment be occupied in useful work, physically active and mentally tranquil. For this reason it is necesary to provide him with work that will prove fruitful in his hands. The product of such work, however, can be of little financial value to the colony.

The general policy for the country will be as follows :-

(1) Segregation of all open cases.

(2) Early diagnosis and observation of new cases, with facilities for immediate treatment of those needing it.

(3) Examination of all contacts every six months over a period of five years.

The programme includes, in addition to institutional work and the training of students and medical men, opportunities for the investigation of the situation in the field.

It appears to us that this Central American State is organising its leprosy policy on essentially modern lines, and this comes as a refreshing piece of news, for the chief information to reach countries abroad concerning the situation in Paraguay is usually information regarding the Chaco War. We should like to congratulate the authorities in Paraguay, and trust that Dr. J. Nairn Hay's memorandum will be speedily implemented. 